\title{
Role of histamine in the aetiology of byssinosis. I Blood histamine concentrations in workers exposed to cotton and flax dusts
}

\author{
M H NOWEIR, H M ABDEL-KADER, AND F OMRAN \\ From the Occupational Health Department, High Institute of Public Health, University of Alexandria, Egypt
}

ABSTRACT The formation or the accumulation, or both, of histamine in the lungs may be potentiated by agent(s) present in cotton dust at higher level(s) than in flax dust and negligible in cottonseed dust. It has been suggested that such potentiation may be due to the activation of the ability of the lung to produce histamine and/or produce or recruit mast cells; this may present an acceptable explanation of the mechanism by which the propagation of the chronic effect of the dust proceeds in cotton and flax workers. Histamine accumulated in the lung over the weekend is released on exposure to dust causing the symptoms of byssinosis. The difference in the rate of histamine metabolism relative to the rate of histamine formation in byssinotic subjects leads to a more prolonged histamine accumulation than in symptom free subjects, with the consequent appearance of the symptoms of byssinosis. Continuous exposure to dust, without weekend interruption, leads to equivalent rates of histamine formation and metabolism with non-considerable histamine accumulation in the lungs and consequent absence of the symptoms of byssinosis.

The antigenic ${ }^{-3}$ and/or non-antigenic, ${ }^{4-7}$ release of histamine, accumulated during the weekend, has been widely accepted as an explanation of the occurrence of the acute symptoms of byssinosis on the first working day of the week after a weekend interruption from work. ${ }^{8}$ It has been suggested that this histamine release is caused by:

(a) Gram-negative bacterial endotoxins found in dust $^{9-13}$;

(b) Agent(s) in dust that form complex(es) with circulating antibody fixing complement fragments with histamine liberation ${ }^{14}{ }^{15}$; or

(c) Pharmacologically active agents ${ }^{5-7}$ 16-22 or a combination of these three.

Histamine release could not explain the propagation of byssinosis, however. In other words, whereas the histamine release could explain the acute response to exposure to dust, it is hard to implicate this in the chronic effect of the dust and it has been suggested that such a chronic effect may be brought about by other agents in the dust. ${ }^{23}$

The present study was conducted to shed light on the role of histamine in the occurrence of the

Received 1 November 1982

Accepted 6 December 1982 chronic effect of exposure to cotton and flax dusts. The hypothesis is that the histamine formed in the workers' lungs will be released on exposure to cotton or flax dust, will circulate in the blood, and will be subjected to metabolism. Also, the formation, release, and metabolism of histamine may be affected by:

(a) The duration and level of dust exposure, as well as the type of dust;

(b) The progression of the grade of byssinosis; and

(c) The schedule of dust exposure relative to the weekend interruption.

\section{Methods and materials}

A random sample of 300 subjects was selected from workers exposed to flax dust in the different operations of flax processing. A sample of 300 workers was also selected from those working in the different operations of the ginning, cotton textile, and cottonseed oil extraction industries. Also, a control group of 50 subjects was randomly selected from workers in the civil service in the same localities as the flax and cotton workers, matching them for age and socioeconomic status. None of the control subjects has been known to have a history of exposure to 
dust.

The selected workers and control subjects were medically examined as described in detail elsewhere, ${ }^{24}$ with special reference to the diagnosis of byssinosis, ${ }^{25}$ chronic bronchitis, and bronchial asthma. ${ }^{26}$ The pulmonary function of the workers was measured on the first day of the working week (Saturday) after a one day weekend (Friday), just before getting to work, and also before the end of the shift (after six to eight hours exposure to dust). It may be noted that the workers in the cotton textile operations have been continuously working (seven days a week) without weekends. A few of these workers performed the pulmonary function measurements when they came after a leave of absence from the work, but most were unable to do so.

Samples of venous blood were collected from the workers and controls into vacutainers containing disodium EDTA. Generally, the workers were randomly stratified and the blood samples were collected from them either:

(a) Before getting into the first shift of the working week after a weekend;

(b) After two hours exposure on the first shift of the working week, or

(c) On the second day of the working week.

For workers exposed to cotton dust in the textile operations, where they have no weekends, samples were taken before getting to their morning shift on any working day.

Histamine was determined in the haemolysed blood by the method of Michaelson and Coffman ${ }^{27}$ as modified by Anton and Sayre. ${ }^{28}$

A parallel study was conducted to assess the level of dust exposure at the different operations where the selected subjects worked, using a vertical elutriator sampler for the assessment of "inhalable" dust $(<15 \mu \mathrm{m})$.

\section{Results}

\section{BLOOD HISTAMINE CONCENTRATIONS OF}

WORKERS EXPOSED TO FLAX DUST

The concentrations of blood histamine in workers exposed to flax dust, classified according to their respiratory diagnosis and according to the results of their pulmonary function measurements, are shown in fig 1 , and represent the mean and standard error for each subgroup. It may be noted that:

(a) The blood histamine concentrations were significantly higher $(p<0.01)$ in all workers than in the controls.

(b) For all the subgroups of workers from whom blood samples were obtained after two hours from the beginning of exposure the concentrations of blood histamine were significantly higher than in the blood of other workers within the same diagnostic group whose samples were collected either before the beginning of exposure or on the second day of exposure $(\mathrm{p}<0.05-0.01)$.

(c) Only in the group of workers diagnosed as having byssinosis, grade II, were the histamine concentrations in the blood samples collected after one

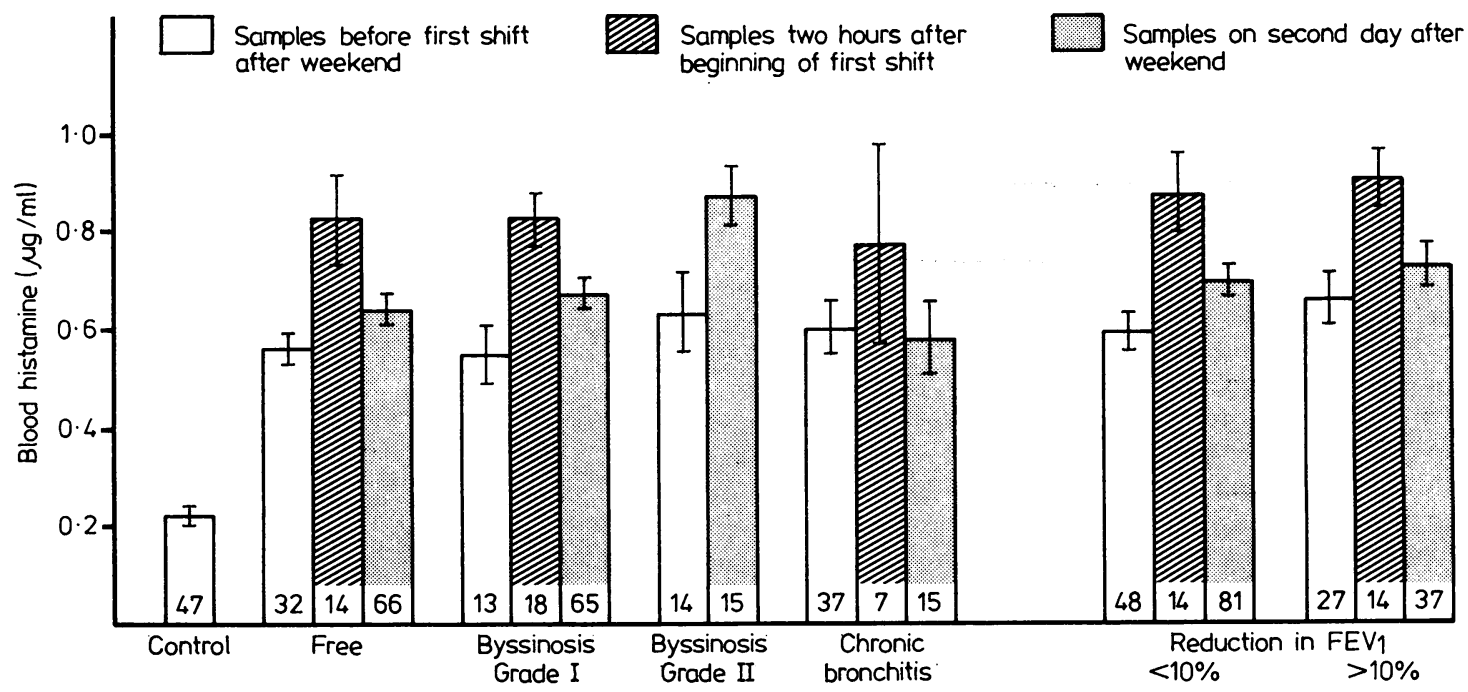




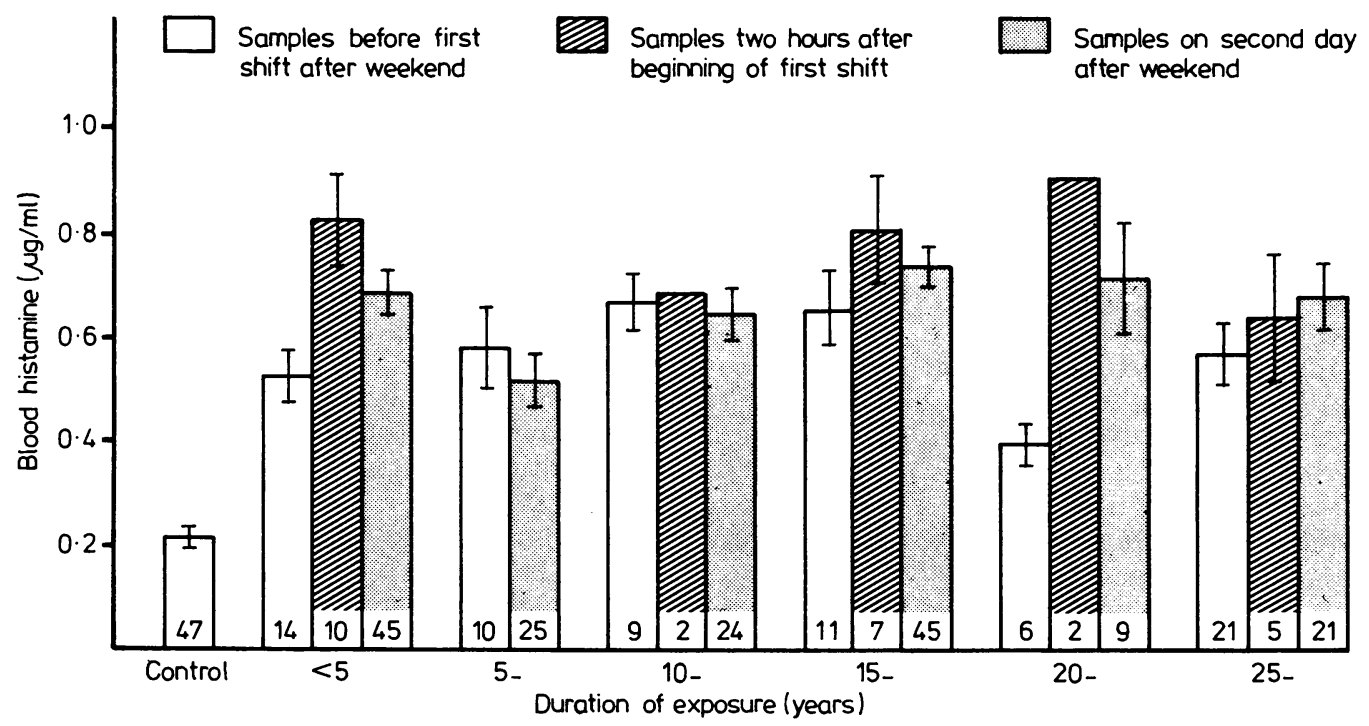

Fig 2 Mean blood histamine concentrations of workers exposed to flax dust for different durations.

day of exposure significantly higher than in those collected before the beginning of exposure $(p<$ 0.05 ).

(d) No significant difference could be observed between the different exposed subgroups of workers diagnosed as having chronic bronchitis.
The distributions of the data of histamine concentrations according to the duration and levels of dust exposure of examined workers are presented in figs 2 and 3 and show that:

(a) The concentrations of blood histamine were significantly increased in workers exposed for rela-

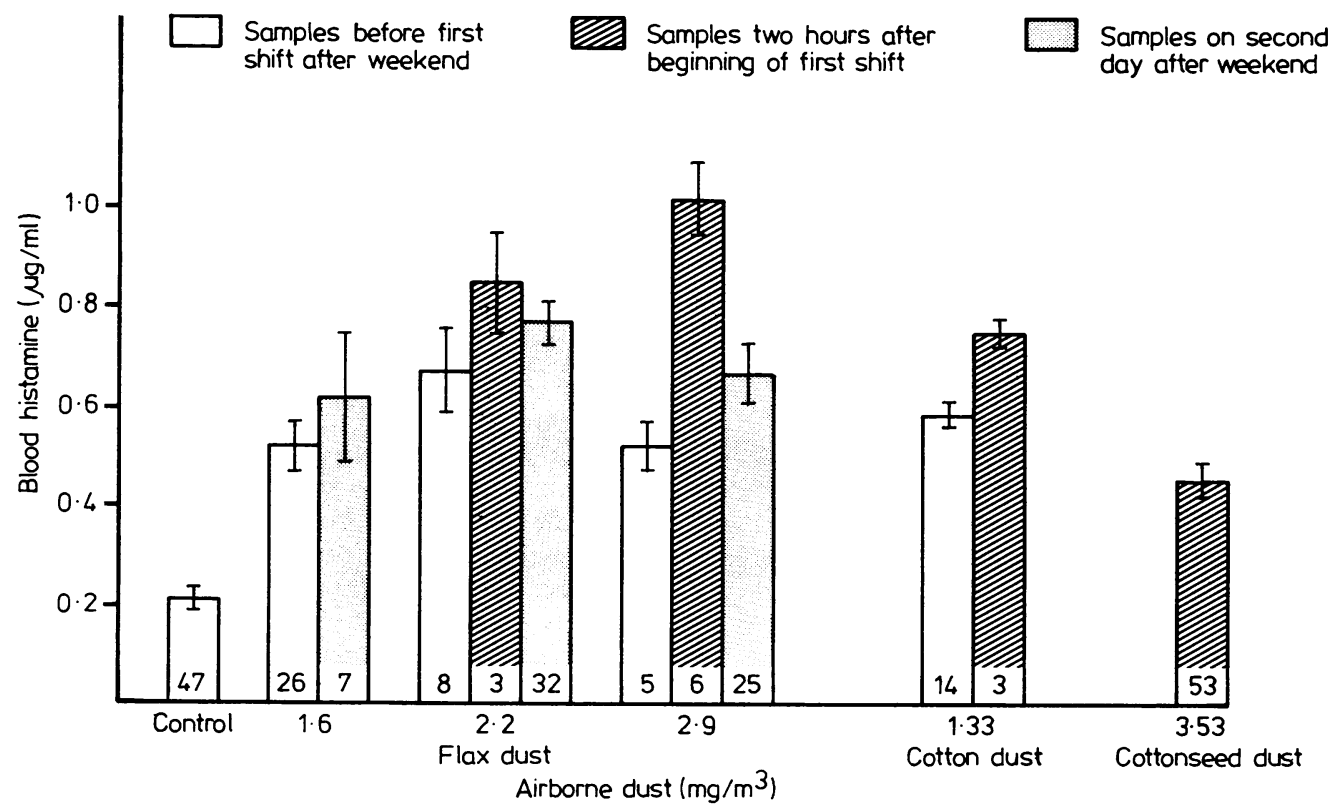

Fig 3 Mean blood histamine concentrations of workers exposed to different concentrations of airborne flax, cotton, or cottonseed dust. 
tively short periods (less than five years) and remained steady on further exposure (fig 2 ).

(b) The blood histamine concentrations showed a steady increase with the levels of exposure; a moderate correlation $(r=0.61)$ was obtained between the blood histamine concentrations and the levels of dustiness to which workers were exposed (fig 3).

\section{BLOOD HISTAMINE CONCENTRATIONS OF WORKERS EXPOSED TO COTTON DUST}

A similar picture to that presented in fig 1 was obtained for workers exposed to cotton dust. It may be noted, however, that the blood histamine concentrations of the 25 workers exposed to cotton dust in ginning and of the 47 cottonseed handling operators in the cottonseed oil extraction industry were significantly higher $(p<0.05-0.01)$ than those of the 53 workers who were exposed to cottonseed dust in the oil extraction operation. Also, the concentrations of blood histamine of the 175 workers who were continuously exposed to textile cotton dust without weekend interruption were significantly lower $(p<0.001)$ than those of the workers handling cottonseed, even though they were exposed to much higher levels of textile dust $\left(2.11,3.29 \mathrm{mg} / \mathrm{m}^{3}\right)$ than the latter group $(1.33 \mathrm{mg} /$ $\left.\mathrm{m}^{3}\right)$. On the other hand while the blood histamine concentrations of the workers in the ginning and cottonseed handling showed a substantial increase in the first years of exposure (less than five years), followed by more or less steady levels on further exposure, in the workers continuously exposed to textile cotton dust no significant difference was found among any of the subgroups exposed for different durations and the control group.

Evaluating the effect of the levels of the different types of dust on the blood histamine concentrations of the exposed workers (fig 3 ) indicated that;

(a) The concentrations of blood histamine of 17 workers exposed to a mean concentration of 1.33 $\mathrm{mg} / \mathrm{m}^{3}$ of cotton dust were significantly higher than those of 33 men exposed to a mean concentration of $1.6 \mathrm{mg} / \mathrm{m}^{3}$ flax $(\mathrm{p}<0.01)$, and

(b) The blood histamine concentrations of the above two groups were significantly higher than those of men exposed to a higher mean concentration $\left(3.53 \mathrm{mg} / \mathrm{m}^{3}\right)$ of cottonseed dust $(p<0.01)$.

\section{Discussion}

HISTAMINE FORMATION AND ACCUMULATION IN WORKERS EXPOSED TO COTTON OR FLAX DUST: EXPLANATION OF THE CHRONIC EFFECT OF DUST EXPOSURE

The results presented indicate a significant increase in the blood histamine concentration of all workers exposed to cotton or flax dust, even if they are free from respiratory complaints (fig 1). Therefore, exposure to these dusts may potentiate the process of histamine formation, with subsequent accumulation of the formed histamine in exposed workers. Such potentiation progressed at a rapid rate in the first years of exposure and slows down on further exposure (fig 2). Consequently, it could be suggested that cotton and flax dusts may contain factors that potentiate the process of histamine formation in the lungs of workers inhaling these dusts; the formed histamine may be subsequently released and translocated into the blood, thus raising the workers' blood histamine load. Previous studies in this laboratory ${ }^{29}$ support the present findings. Cotton dust extract significantly increased the histamine forming capacity (HFC) of guinea pig stomach glandular cells preparation in vitro; the increase was greater in the presence of relatively higher concentrations of the extract. In another study (part II), ${ }^{30}$ however, no histamine decarboxylase activity could be detected in the lungs of guinea pigs chronically exposed to cotton and flax dusts, nor in control animals. Consequently, the increase in the histamine forming capacity in the lung may be due to the increase in the ability of the lung to produce or recruit mast cells or both. For example, some cells have been reported to be recruited into rats' airway walls in vivo on their exposure to cotton cardroom dust. ${ }^{31}$

The potentiation of histamine formation in the lungs of workers exposed to cotton or flax dust by agents present in the dust is suggesed as an explanation of the mechanism by which the propagation of the chronic effect of dust proceeds. Harris et al have proposed that the chronic effect of dust may be caused by agents in cotton dust other than those responsible for the acute effect ${ }^{23}$ - that is, the release of histamine and the occurrence of the symptoms of byssinosis on exposure to dust on the first workday of the week after the weekend. Such potentiation progresses by duration and level of dust exposure, especially in the first years of exposure (figs 2 and 3 ), and to a lesser extent by the propagation of the symptoms of byssinosis (fig 1).

Evidence has also been presented that the agents responsible for the formation and accumulation of histamine may be present at higher levels in cotton dust than in flax dust and that their concentration in cottonseed dust is mostly negligible. The latter type of dust has been reported to be acting as an "inert dust" with regard to the development of byssinosis. ${ }^{32}$ On the other hand, previous studies on experimental animals in this laboratory have shown that cotton dust may be more potent than flax dust. Guinea pigs exposed to cotton cardroom dust $(0 \cdot 6-$ 
$0.7 \mathrm{mg} / \mathrm{m}^{3}$ respirable dust) for different durations (4-24 weeks) had more histamine in the lung tissue (201-464 $\mu \mathrm{g} / \mathrm{g}$ dry tissue) than animals exposed to considerably higher concentrations of flax dust $\left(2 \cdot 8-5 \cdot 2 \mathrm{mg} / \mathrm{m}^{3}\right)$; the histamine content in the lungs of the latter animals was considerably lower (23-27 $\mu \mathrm{g} / \mathrm{g}$ dry tissue) (part II). ${ }^{30}$

Part of the formed histamine is anticipated to be spontaneously released and translocated into the blood, as indicated from the significantly higher concentrations of blood histamine observed in all exposed workers by comparison with control subjects. The slight increase in the blood histamine load of byssinotic workers, however, compared with workers free from respiratory symptoms may be interpreted on the basis either of the development of hypoxia, which leads to reduction in the histamine forming capacity, ${ }^{27}$ or to the relative increase in the histamine catabolising activity of exposed workers. Such an increase in histamine metabolism, however, might not proceed to the same extent as the increase in histamine formation.

\section{HISTAMINE RELEASE AND METABOLISM VERSUS} DIAGNOSIS OF BYSSINOSIS

In almost all groups of workers examined the blood histamine concentrations increased significantly on exposure to dust, indicating the release of histamine accumulated in the lungs during the weekend, with the occurrence of symptoms of byssinosis, and consequent translocation of histamine into the blood. This was followed by a decrease of blood histamine concentrations on the second day of the working week; such a decrease was significant in most of the groups examined, but highly significant only in those who were free from any respiratory symptoms $(\mathrm{p}<$ 0.001).

The observed differences in blood histamine concentrations on the second day of exposure could be due to differences in the rate of histamine metabolism relative to the rate of histamine formation in the different groups. The rate of histamine metabolism may progress in parallel with the rate of histamine formation in subjects free from symptoms, whereas in byssinotic subjects it may progress at relatively lower rates. This is accompanied by a higher accumulation of histamine in the byssinotic subjects than in the symptom free subjects, with a consequent prolonged appearance of chest tightness and breathlessness. This view may be further supported by the data derived from animal experiments in this laboratory. For example, the exposure of guinea pigs to flax or cotton dust for 24 weeks resulted in a complete loss of methylating enzyme activity in the lungs; such activity has been shown to comprise the major proportion of the histamine catabolising activ- ity in control animals (part II). ${ }^{30}$ It has also been shown that diamine oxidase activity was significantly reduced in the small intestine of rats injected with cotton dust extract or subjected to chronic dust inhalation $^{29}$; such a reduction in activity would reduce the catabolism of histamine.

This variation in the rate of histamine metabolism between the symptom free and byssinotic subjects, while it may be affected by some components in cotton and flax dust which cause reduction in the "enzymatic histamine catabolism activity," may also be due to some personal factors of the exposed workers. In other words, subjects with relatively hindered histamine metabolism would be more liable to develop byssinosis than subjects with a relatively better histamine metabolism and, consequently, the former will be more "reactive" to dust exposure and development by byssinosis than the latter. ${ }^{33}$

In workers continuously exposed to cotton dust with no weekend interruption the rate of histamine formation is almost equivalent to the rate of histamine metabolism, with no accumulation in the lung and consequently an absence of the symptoms of byssinosis.

Supported by the PL-480 agreement No 03-004-C of the USPHS (NIOSH).

Requests for reprints to: Professor Madbuli H Noweir, High Institute of Public Health, 165 Horria Avenue, Hadra, Alexandria, Egypt.

\section{References}

' Massoud A, Taylor G. Byssinosis antibody to cotton antigens in normal subjects and cotton card-room workers. Lancet 1964; ii:607-10.

2 Taylor G, Massoud A, Lucas F. Studies on the aetiology of byssinosis. Br J Ind Med 1971;28:143-51.

${ }^{3}$ Schlueter DP. Response of the lung to inhaled antigens. Am J Med 1974;57:476-92.

4 Bouhuys A, Lindell SE. Lindin D. Experimental studies on byssinosis. Br Med J 1960;i:324-6.

5 Bouhuys A, Lindell SE. Release of histamine by cotton dust extracts from human lung tissue in vitro. Experianta 1961;17:211-5.

- Nicholls PJ, Nicholls GR, Bouhuys A. Histamine release by compound $48 / 80$ and textile dusts from lung tissue in vitro. In: Davies $\mathrm{CN}$, ed. Inhaled particles and vapours II. London: Pergamon Press, 1966:69-74.

7 Antweiller H, Pelberg R. New findings about biologically active substances in cotton dust. XVIII International Congress of Occuptional Health (abstracts), Brighton, 14-19 September 1975: Geneva: Permanent Commission and International Association on Occupational Health, 101.

${ }^{8}$ Schilling RSF. Byssinosis. In: Muir DCF, ed. Clinical aspects of inhaled particles. Philadelphia: Heinemann, 1972;77-85.

${ }^{9}$ Furness G, Maitland HB. Studies on cotton dust in relation to byssinosis. Part I: bacteria and fungi in cotton dust. $\mathrm{Br} J$ Ind Med 1952;2: 138-45. 
${ }^{10}$ Tuffnell $P$. The relationship of byssinosis to the bacteria and fungi in the air of textile mills. Br J Ind Med 1960;17:304-6.

"Pernis B, Vigliani EC, Cavagna G. The role of endotoxins in the pathogenesis of dust diseases in textile workers. Med Lav 1960;51:753-803 (Bull Hyg 1961;36:530.

12 Pernis B, Vigliani EC, Cavagna G, Finulli M. The role of bacterial endotoxins in occupational diseases caused by inhaling vegetable dusts. Br J Ind Med 1961;18:120-9.

${ }^{13}$ Cavagna G, Foa V, Vigliani EC. Effects on man and rabbits of inhaling of cotton dust or extracts and purified endotoxins. $\mathrm{Br}$ $J$ Ind Med 1969;26:314-21.

${ }^{14}$ Snell JD. Effects of inhaled endotoxins. J Lab Clin Med 1966;67:624-7.

15 Edwards JH, Jones BM. Pseudoimmune precipitation by the isolated byssinosis "antigen." J Immunol 1973;110:498-501.

${ }^{16}$ Antweiller $\mathbf{H}$. Observation about a histamine liberating substance in cotton dust. Ann Occup Hyg 1960;2:152-6.

${ }_{17}$ Antweiller H. Histamine liberation by cotton dust extracts: evidence against its causation by bacterial endotoxins. $\mathrm{Br} J$ Ind Med 1961;18:130-3.

${ }^{18}$ Evan E, Nicholls PJ. Distribution of histamine releasing activity in gossypium hirsutum. J Pharm Pharmacol 1973;25 (suppl): 141-2.

${ }^{19}$ Evan E, Nicholls PJ. Studies of the mechanism of histamine release from lung tissue in vitro by cotton dust extracts. Agents and Actions 1974;5:304-10.

${ }^{20}$ Evan E, Nicholls PJ. Preliminary characterization of the histamine releasing activity of cotton dust. J Pharm Pharmacol 1974;26 (suppl):115-6.

${ }^{21}$ Hitchcock M, Piscitelli DM, Bouhuys A. Histamine release from human lung by a component of cotton bracts and by compound 48/80. Arch Environ Health 1973;26:177-82.

${ }^{22}$ Buck MG, Bouhuys A. Byssinosis airway constructor in cotton bract. Lung 1980;158:25-32.

${ }^{23}$ Harris TR, Merchant JA, Kilburn KH, Hamilton JD. Byssinosis and respiratory diseases of cotton mill workers. JOM
1972;14:199-205.

${ }^{24}$ Noweir MH, El-Sadek YM, El-Dakhakhny AA, Osman HA. Dust exposure in manual flax processing in Egypt. $\mathrm{Br} J$ Ind Med 1975;32:147-54.

${ }^{25}$ Schilling RSF, Vigliani EC, Lammers B, Valic F, Gilson J. A report on a conference on byssinosis. XIV International Congress of Occupational Health. Madrid, Spain, 16-21 Sept 1963. International Congress series No 62, New York, NY: Excerpta Medica Foundation, 1963:137-45.

${ }^{26}$ Fletcher CM. Chronic bronchitis. Am Rev Respir Dis 1959;80:483-94.

${ }^{27}$ Michaelson IA, Coffman PZ. An improved ion-exchange purification procedure for the fluorometric assay of histamine. Anal Biochem 1969;27:257-61.

${ }^{28}$ Anton AH, Sayre DF. A modified fluorometric procedure for tissue histamine and its distribution in various animals. $J$ Pharmacol Exp Ther 1966;166:285-92.

${ }^{29}$ Ghoneim MT, El-Dakhakhny M, Noweir MH. "In vitro" and "in vivo" effect of cotton dust on the histamine forming capacity and diamine oxidase activity in rats. J Egypt Public Health Assoc 1975;50:394-407.

${ }^{30}$ Noweir MH, Abdel-Kader HM, Makar A. Role of histamine in the aetiology of byssinosis-part II. Lung histamine in guinea pigs chronically exposed to cotton and flax dusts. $\mathrm{Br} J$ Ind $\mathrm{Med}$ 1984;40:209-15.

${ }^{31}$ Kilburn KH, McKenzie WH. Leucocyte recruitment to air-ways by condensed vegetable tannins and quercetin. Lab Invest 1973;28:55-9.

${ }^{32}$ Noweir MH, El-Sadek YM, El-Dakhakhny AA. Exposure to dust in the cottonseed oil extraction industry. Arch Environ Health 1969;19:99-102.

${ }^{33}$ Noweir MH. Broad spectrum industrial hygiene research activities in a developing country-Egypt. The Yant memorial lecture. Am Ind Hyg Assoc J 1979;40:839-59. 